\title{
ACESSO À JUSTIÇA: ÊNFASE NA DIFUSÃO DE INFORMAÇÕES JURÍDICAS À SOCIEDADE DE MANEIRA GERAL
}

\section{ACCESS TO JUSTICE: EMPHASIS ON THE DISSEMINATION OF INFORMATION TO THE GENERAL LEGAL WAY TO SOCIETY}

Luís Henrique Bortolai

Doutorando em Direito pela Faculdade Autônoma de Direito - FADISP. Professor de Direito na Universidade Presbiteriana Mackenzie, campus Campinas. E-mail: borto04@hotmail.com

Recebido em: 06/01/2016

Aprovado em: 26/04/2016

Doi: $10.5585 / \mathrm{rdb} . v 14 \mathrm{i} 6.313$

\begin{abstract}
RESUMO: Abordagem ímpar, capaz de unir o princípio do acesso à justiça com a disseminação de conhecimento, possibilitando que a interpretação seja realizada da maneira mais livre e desimpedida possível, por meio de métodos interpretativos que possibilitem uma melhor aplicação dos dispositivos, materializando a norma constitucional. Por meio de uma análise ampla e capaz de apresentar os anseios da sociedade, busca-se apresentar como uma das soluções ao problema jurídico atual, a capacitação das pessoas, de modo a possibilitar que estas reivindiquem seus direitos quando feridos, seja em caráter individual ou coletivo. Por fim, almeja-se uma releitura da atual conjuntura brasileira, de modo a realmente repensar o direito na vida das pessoas.
\end{abstract}

Palavras-chave: Acesso à justiça. Informação. Disseminação. Estado.

\begin{abstract}
Unique approach, able to unite the principle of access to justice to the dissemination of knowledge, enabling the interpretation is performed in the most free and unimpeded possible, through interpretive methods that enable better application of the devices, materializing the constitutional norm. Through a wide and able analysis to present the concerns of society, seeks to present itself as one of the solutions to the current legal problem, the empowerment of people so as to enable these to claim their rights when injured, either on an individual basis or collective. Finally, a reinterpretation we aim of the current Brazilian situation, in order to really rethink the law in people's lives.
\end{abstract}

Keywords: Access to justice. Information. Dissemination. State.

SUMÁRIO: Introdução; Desenvolvimento; Conclusão; Referências Bibliográficas.

\section{INTRODUÇÃO}

Antes de iniciar qualquer tipo de debate, necessário realizar uma pequena introdução do assunto. $\mathrm{O}$ acesso à justiça, garantido no texto constitucional, não pode ser apenas uma letra apresentada no plano teórico. É necessário que a população tenha realmente conhecimento, de como efetivar esta garantia. Por isso que da presente proposta, de aproximação do direito do quotidiano das pessoas, de modo a possibilitar esta nova leitura do acesso à justiça, por meio de 
uma ampliação de seus fundamentos, bem como de uma nova leitura sobre o tema, especialmente ao possibilitar uma melhor compreensão por parte das pessoas de maneira geral.

A questão aqui não é querer encontrar um culpado (seria a linguagem jurídica o grande problema de interpretação ou a educação dada aos brasileiros que não os permite entender a letra da lei?), mas colocar em pauta a acessibilidade da norma jurídica àqueles que são destinatários dela por direito, analisando questões que vão desde o problema educacional do Brasil até o rebuscamento da linguagem da norma jurídica. Passando por uma reanálise da importância do tema no dia-a-dia das pessoas, aliada a uma proposta diferenciada de reinterpretação do assunto.

Os métodos utilizados serão: argumentativo (análise de elementos e estratégias que corroborem com o fim almejado por este trabalho), descritivo (descrição da situação de fato e correlação com as demais situações que a envolvem), analítico (aprofundamento de um estudo com o fim de explicar a formação de determinado fenômeno) e bibliográfico (leitura de livros, artigos, jurisprudências com o fim de embasar esta pesquisa).

A opção por estes métodos se deu devido às peculiaridades da proposta feita na presente tese, especialmente ao aliar estudos teóricos, com uma abordagem prática, baseada no estudo empírico. Além disso, indispensável a realização de uma leitura bibliográfica apurada e especializada para a presente leitura, aliada à uma abordagem prática, de modo a realmente colocar a teoria confrontada dentro de uma realidade.

\section{DESENVOLVIMENTO}

O acesso à justiça, tão preconizado nas ciências jurídicas e sociais, especialmente na atualidade, será abordado na presente análise, sob uma óptica diferenciada. A partir de uma leitura muito mais próxima da população, seja ela qual for a sua camada social, buscando apresentar um acesso ao conhecimento jurídico, que pode se desdobrar em um acesso à verdadeira justiça, sendo o papel exercido pelo Poder Judiciário ainda mais relevante face ao atual cenário nacional, especialmente com os problemas e anseios que a sociedade pós-moderna tem passado. Kazuo Watanabe assim já se posicionou:

A problemática do acesso à justiça não pode ser estudado nos acanhados limites do acesso aos órgãos jurisdicionais já existentes. Não se trata apenas de possibilitar o acesso à justiça enquanto instituição social, e sim viabilizar o acesso à ordem jurídica justa. ${ }^{1}$

A presente análise tem como foco principal, apresentar uma leitura diferenciada do princípio do acesso à justiça, não somente no que tange à vertente processual, mas sim sobre a inserção social desta garantia constitucional, especificamente na transmissão do conhecimento, em face de segmentos da sociedade que não possuem noção de muitos dos seus direitos.

Ao abordar o tema, Humberto Peña de Moraes e José Fortenelle Teixeira da Silva assim se manifestam:

Com efeito, de que vale o Estado assegurar direitos aos deserdados, se ele próprio não oferece quem os defenda e garanta? De que vale o Estado prometer a jurisdição, se somente os afortunados podem invocar-lhe a prestação? Por onde andará a Justiça? Justiça para alguns não é justiça, e, sim, odiosa discriminação, incompatível com os conceitos do Estado moderno. ${ }^{2}$

\footnotetext{
${ }^{1}$ WATANABE, Kazuo. Acesso à justiça e sociedade moderna. In: Participação e Processo. 1 ed. São Paulo: Revista dos Tribunais, 1988, p. 128.

${ }^{2}$ DE MORAES, Humbero Peña; DA SILVA, José Fontenelle Teixeira. Assistência judiciária: sua gênese, sua história e a função protetiva do Estado. 2. ed. Rio de Janeiro: Liber Juris, 1994, p. 144. 
Um contato mais próximo dos meios de solução de conflitos, sejam eles os habituais, como o Poder Judiciário, sejam os alternativos, como por exemplo, a mediação e a conciliação, que hoje tem se popularizado e se disseminado no âmbito nacional, especialmente face a ineficiência do judiciário, na busca de solução de conflitos e na materialização da tão almejada paz social e segurança nas relações firmadas, se mostra fundamental. Os próprios cursos de graduação em ciências jurídicas e sociais estão sendo repensados de modo a conseguir realocar tais dispositivos na grade curricular, possibilitando assim a formação de novos profissionais, aptas a se depararem com esta realidade, de acordo com os seus anseios.

A utilização dos métodos clássicos de interpretação, ao possibilitar a leitura dos dispositivos, tem se relevado insuficientes e não tem alcançado o verdadeiro núcleo essencial preceituado pela norma constitucional, de facilitar o contato com uma resolução do litígio ali apresentado, de modo satisfatório. Nesse sentido ensina Luis Roberto Barroso:

A ideia de uma nova interpretação constitucional liga-se ao desenvolvimento de algumas fórmulas originais de realização da vontade da Constituição. Não importa em desprezo ou abandono do método clássico - o subsuntivo, fundado na aplicação de regras - nem dos elementos tradicionais da hermenêutica: gramatical, histórico, sistemático e teleológico. Ao contrário, continuam eles a desempenhar um papel relevante na busca de sentido das normas e na solução de casos concretos. Relevante, mas nem sempre suficiente. [...] Portanto, ao se falar em nova interpretação constitucional, normatividade dos princípios, ponderação de valores, teoria da argumentação, não se está renegando o conhecimento convencional, a importância das regras ou a valia das soluções subsuntivas. Embora a história das ciências se faça, por vezes, em movimentos revolucionários de ruptura, não é disso que se trata aqui. A nova interpretação constitucional é fruto de evolução seletiva, que conserva muitos dos conceitos tradicionais, aos quais, todavia, agrega idéias que anunciam novos tempos e acodem a novas demandas. ${ }^{3}$

Portanto, na aplicação de uma disposição constitucional, deve-se ater aos fins sociais a que ela foi criada, buscando o bem estar da coletividade, seguindo o preceito disposto no artigo $5^{\circ}$ da Lei de Introdução às Normas do Direito Brasileiro (Decreto-Lei $\left.n^{\circ} 4.657 / 42\right)^{4}$. Nesta esteira ainda, outro método apresentado se mostra relevante e propício a presente proposta, vez que possibilita, ainda segundo as palavras de Luís Roberto Barroso a:

[...] atribuição de novos conteúdos à norma constitucional, sem modificação do seu teor literal, em razão de mudanças históricas ou de fatores políticos e sociais que não estavam presentes nas mentes dos constituintes. ${ }^{5}$

Com isso, a aplicação conjunta destes métodos interpretativos, confere a presente análise uma leitura diferenciada e ao mesmo tempo relevante. Alfredo Augusto Becker pondera em quatro etapas o ato de interpretação da lei, quais sejam:

\footnotetext{
${ }^{3}$ BARROSO, Luis Roberto. Começo da história. A nova interpretação constitucional e o papel dos princípios no direito nrasileiro. In SILVA, Virgílio Afonso da (org.). Interpretação Constitucional. São Paulo: Malheiros, 2005 p. 04/07.

4 BRASIL. Decreto Lei n. 4.657/42. Lei de Introdução às Normas do Direito Brasileiro. Brasília: Senado, 2013. "Na aplicação da lei, o juiz atenderá aos fins sociais a que ela se dirige e às exigências do bem comum."

5 BARROSO, Luís Roberto. Interpretação e aplicação da Constituição: fundamentos de uma dogmática constitucional transformadora. 7 ed. rev. São Paulo: Saraiva, 2009, p. 137.
}

Revista de Direito Brasileira | São Paulo, SP | v. 14 | n. 6 | p. 128- 138 | maio/ago. 2016 
1) Distinção dos elementos da hipótese de incidência da regra jurídica em apreço; 2) Estudo prévio das consequências da regra jurídica; 3) Análise de todos os fatos da hipótese de incidência, de modo a preencher todas as lacunas apresentadas; e 4) Ponderar se as consequências da regra de incidência foram respeitadas. ${ }^{6}$

Diante disso, o método de interpretação que melhor se coaduna com as disposições do texto constitucional, é aquele que busca trazer maior efetividade as suas disposições, sendo uma abordagem ampliativa a melhor forma de materializar tal disposição. Além do que, um elemento histórico se mostra essencial para o desenvolvimento do presente debate, vez que, quando da promulgação da Constituição da República Federativa do Brasil, em 1988, cabia ao intérpreteaplicador buscar a verdadeira finalidade da norma, possibilitando a eficácia plena das suas apresentações.

Além disso, o intérprete-aplicador deve enfrentar este questionamento com um olhar crítico, buscando se libertar das amarras da literalidade, efetivando as disposições constitucionais, principalmente aquelas que possibilitam a difusão de conhecimento, de forma ampla e irrestrita, concretizando as disposições contidas no texto constitucional. Segundo Bernardo Ribeiro de Moraes, "[...] está na preservação, proteção e estímulo dos valores éticos e culturais agasalhados pelo Estado".

De fato, não se pode interpretar um preceito fundamental como se interpreta uma norma infraconstitucional, por exemplo. A norma constitucional foi encartada no texto maior para a proteção de valor fundamental da humanidade, o acesso ao conhecimento, sem a qual não se pode falar em uma efetiva democracia participativa. Tendo em vista isso, deve ser atribuído o sentido que traga maior eficácia a estas disposições. José Joaquim Gomes Canotilho faz menção ao princípio da máxima efetividade, ou seja, diante de uma situação conflitante, deve-se proceder pela aplicação do método mais condizente com a realidade fática, de forma a possibilitar a maior inclusão possível do dispositivo ${ }^{8}$. Outro pensador bem pontual a presente demanda é Konrad Hesse, ao afirmar que a interpretação do texto constitucional sempre deve almejar a sua efetiva concretização. Segundo aludido doutrinador, "o que não aparece de forma clara como conteúdo da Constituição é o que deve ser determinado mediante a incorporação da 'realidade' de cuja ordenação se trata". 9 '

A interpretação de norma constitucional sempre necessita de cuidados. Atento ao princípio da supremacia constitucional, não pode o intérprete-aplicador se esquivar, uma vez que a Carta Magna alberga os princípios fundamentais do Estado Democrático e Social de Direito e que na interpretação de suas normas, deve se buscar um bem coletivo maior. Tais princípios devem ser ponderados como um conjunto harmônico e não podem ser subjulgados por força das formas literárias que infelizmente ainda dominam muitos juristas.

Para Paulo Bonavides, ao tratar dos métodos de interpretação da nova hermenêuticaque:

A adaptação da Constituição à sua época preocupa de maneira constante o formulador da nova concepção interpretativa, tanto que ao fator tempo atribui importância capital. Não é à toa que ele assevera "viver o Direito Constitucional prima face numa específica problemática de tempo." e que "a continuidade da Constituição somente é possível quando o passado e o futuro se acham nela conjugados." A controvérsia acerca dos métodos no Direito

6 BECKER, Alfredro Augusto. Teoria geral do direito tributário. São Paulo: Saraiva, 1963, p. 272.

7 DE MORAES, Bernardo Ribeiro. A imunidade tributária e seus novos aspectos. In MACHADO, Hugo de Brito (coord.). Imunidades tributárias. São Paulo: CEU/Revista dos Tribunais, 1998, p. 107.

${ }^{8}$ CANOTILHO, José Joaquim Gomes. Direito constitucional. Coimbra: Almedina, 1989, p. 162.

9 HESSE, Konrad. Escritos de Derecho Consticional. Trad. Pedro Cruz Villalon, Madrid: Centro de Estudios Constitucionales, 1992, p. 40.

Revista de Direito Brasileira | São Paulo, SP | v. 14 | n. 6 | p. 128- 138 | maio/ago. 2016 
Constitucional é, em última análise, segundo Häberle, uma luta acerca do papel que deve caber ao tempo. A velha hermenêutica, pelo seu caráter mais estático que dinâmico, deve ser vista como instrumento por excelência das ideologias do 'status quo'. A interpretação concretista, por sua flexibilidade, pluralismo e abertura, mantém escancaradas as janelas para o futuro e para as mudanças mediante as quais a Constituição permanece estável na rota do progresso e das transformações incoercíveis, sem padecer abalos estruturais, como os decorrentes de uma ação revolucionária atualizadora. ${ }^{10}$

Utilizando-se da interpretação teleológica, atentando-se para a finalidade da norma constitucional, conclui-se que esta deve abranger o acesso ao conhecimento, sob pena de ser tal norma ser utilizada, sem concretizar seu real objetivo. De todo modo, mesmo sem se aprofundar em outros aspectos da doutrina do moderno constitucionalismo, a razão parece estar como leciona Afonso Arinos de Melo Franco, segundo o qual a técnica de interpretação constitucional:

[...] é predominantemente finalística, isto é, tem em vista extrair do texto aquela aplicação que mais se coadune com a eficácia social da lei constitucional. Esta interpretação construtiva permite, em determinadas circunstâncias, verdadeiras revisões do texto, sem que seja alterada a sua forma. $^{11}$

A Carta Magna, fonte de toda forma de interpretação do ordenamento jurídico brasileiro, também pontua em seu artigo 215, que "O Estado garantirá à todos o pleno exercício dos direitos culturais e acesso às fontes da cultura nacional, a apoiará e incentivará a valorização e a difusão das manifestações culturais". Assim, diante destas disposições, fica mais do que evidenciado a necessidade de uma constante atualização e reestruturação das disposições existentes, adaptando tais análises, a formas mais modernas de interpretação e aos anseios sociais.

Portanto, uma aproximação entre o conhecimento, especificamente o jurídico, e a população de modo geral, se mostra uma via extremamente útil e capaz de suprir, ainda que minimamente, as necessidades sociais. Muitas vezes, o simples esclarecimento, de questões que a princípio são tidas como simples, assumem relevante papel, ao esclarecer e informar a pessoa acerca de um direito básico e essencial em seu quotidiano.

A sociedade tem evoluído num ritmo frenético, algo que não vem sendo acompanhado pelo ordenamento jurídico, especialmente acerca da liberdade de expressão e de opinião, seja por meio dos meios de comunicação tidos como clássicos como os jornais e revistas, seja pelas novas mídias, vinculadas especialmente às mudanças trazidas com a tecnologia da informática. A Declaração Universal dos Direitos do Homem, que já no pós-guerra, em 1948, tutelou a todo o direito de "receber e transmitir informações e ideias", seja no âmbito individual, seja no coletivo. A doutrinadora Helena Abdo traz importante diferenciação entre três direitos básicos: a) de informar: garantido constitucionalmente pela disposição do artigo 220, caput, da Constituição Federal da República Federativa do Brasil ${ }^{12}$, buscando tutelar o particular em detrimento do autoritarismo do Estado, representado há pouco tempo pela censura. Tal manifestação sempre deve se pautar pela objetividade, evitando a ocorrência de qualquer veiculação distorcida e deturpadora; ${ }^{13}$ b) de se informar: buscando as informações que desejam, sem qualquer tipo de

10 BONAVIDES, Paulo. Curso de Direito Constitucional. 7. ed. São Paulo: Malheiros, 1997, p. 471.

${ }^{11}$ FRANCO, Afonso Arinos de Melo. Direito constitucional, teoria constitucional, as constituições do Brasil. Rio de Janeiro: Revista Forense, 1976, p. 116.

12 BRASIL. Constituição Federal da República Federativa do Brasil. Brasília: Senado, 1988. "A manifestação do pensamento, a criação, a expressão e a informação, sob qualquer forma, processo ou veículo não sofrerão qualquer restrição, observado o disposto nesta Constituição.”

13 ABDO, Helena. Mídia e processo. São Paulo: Saraiva, 2011, p. 36.

Revista de Direito Brasileira | São Paulo, SP | v. 14 | n. 6 | p. 128- 138 | maio/ago. 2016 
imposição ou restrição de escolhas. Tal subdivisão também é tutelada pelo direito constitucional, especificamente no artigo $5^{\circ}$, inciso XIV da Constituição Federal. ${ }^{14}$ Este direito é essencial como forma de garantir à discussão e o debate dos pontos de vista, garantindo a todos o acesso às diversas fontes, desde que resguardados os direitos inerentes a todas as pessoas, ${ }^{15}$ e c) de ser informado: ou seja, de ser corretamente informado dos fatos, sejam os referentes à própria pessoa, seja os disseminados por toda a coletividade. Tal preceito inclusive assumiu feição de bem de consumo ${ }^{16}$, influenciando de forma determinando nas escolhas das pessoas. ${ }^{17}$

A opinião pública tem moldado o pensamento de boa parte das camadas sociais, impondo seu ponto de vista sobre os demais, levando a uma verdadeira uniformização de pensamentos. ${ }^{18}$ Ocorre que esta imposição não deve prosperar, uma vez que delimita e restringe o conhecimento apresentando, de acordo com a classe vinculante de tais pontos. Outro intelectual que aborda muito bem a esfera pública é Junger Habermas, ao afirmar que a opinião geral é formada não a partir do somatório de pontos de vistas individuais, mas sim de uma opinião da coletividade, que debate e aprofunda os temas ali apresentados, chegando a um consenso final. A opinião pública difere da opinião da maioria, pois a primeira é muito mais concisa, ao estabelecer diversos pontos de vista sobre o mesmo tema, ainda que contrários à linha mestre, possibilitando uma abordagem mais precisa da proposta, enquanto que a segunda apenas toda como base a questão aritmética da questão. ${ }^{19}$

Um tratamento mais igualitário, e ao mesmo tempo mais humano, possibilitaria uma verdadeira materialização de direitos, algo tão preconizado pelo texto constitucional, e agora buscando a sua efetivação frente às necessidades das pessoas, especialmente das mais necessitadas.

O tema, acesso à justiça, não é recente, seja no Brasil, seja no mundo. Por volta da década de 60, ainda no século XX, Mauro Cappelletti e Bryant Garth já debatiam este assunto e inclusive preconizaram uma obra que é tida como referência até os dias de hoje, intitulada "acesso à justiça". Em tal disposição, foi apresenta ao mundo as três ondas renovatórias do acesso à justiça ${ }^{20}$, quais seja, a garantia de uma adequada representação legal aos mais necessitados; a materialização de ações coletivas, em prol do interesse geral e a efetivação real e material do acesso à justiça, por meio de procedimentos mais simples e acessíveis. Tais balizas apresentadas, até hoje influenciam e possibilitam novas leituras e análises dos problemas atuais, possibilitando que o intérprete-aplicador possa ter grande margem de liberdade para buscar a materialização deste dispositivo.

Hugo Nigro Mazzilli assim já se manifestou:

Nos processos, o reinado ainda é das formalidades; sobrevivem registros primitivos à mão, por datilografia, estenotipia ou digitação; juntam-se cópias inúteis de documentos; das audiências, as partes fazem perguntas ao juiz, que as

\footnotetext{
14 BRASIL. Constituição Federal da República Federativa do Brasil. Brasília: Senado, 1988. “Todos são iguais perante a lei, sem distinção de qualquer natureza, garantindo-se aos brasileiros e aos estrangeiros residentes no país a inviolabilidade do direito à vida, à liberdade, à igualdade, à segurança e à propriedade, nos termos seguintes: [...] XIV - É assegurado a todos o acesso à informação e resguardado o sigilo da fonte, quando necessário ao exercício profissional.”

${ }_{15}$ ABDO, Helena. Mídia e processo. São Paulo: Saraiva, 2011, p. 37.

16 DE CARVALHO, Luiz Gustavo Grandinetti Castanho. Liberdade de informação e o direito difuso à informação verdadeira. 2. ed. Rio de Janeiro: Renovar, 2003, p. 209/216.

${ }_{17}$ ABDO, Helena. Mídia e processo. São Paulo: Saraiva, 2011, p. 39.

18 FARIAS, Edilson. Liberdade de expressão e comunicação: teoria e proteção constitucional. São Paulo: Revista dos Tribunais, 2004, p. 124/125.

19 HABERMAS, Junger. Historia y crítica de la opinión pública: la transformación estructural de la vida pública. 4. ed. Barcelona: Gustavo Gilo Eds., 2005, p. 102/145.

${ }^{20}$ CAPPELLETTI, Mauro; GARTH, Bryant. Acesso à justiça. Trad. Ellen Gracie Northfleet. 1. ed. Porto Alegre: Sergio Antonio Fabris Editor, 1988, p. 35.

Revista de Direito Brasileira | São Paulo, SP | v. 14 | n. 6 | p. 128- 138 | maio/ago. 2016
} 
refaz às testemunhas e dita as respostas ao escrevente; falta um índice nos autos (com menção à página de cada ocorrência mais importante, como as citações, intimações da sentença a cada parte etc); não há efetivas ou suficientes sanções para juízes, promotores e advogados que retêm autos além dos prazos; fica sem maiores consequências concretas o fato de as pessoas mentirem ou falarem a verdade; mantém-se um sistema recursal extremamente completo, sem sanção prática alguma para recursos improvidos; depois, há desmedida demora na solução dos casos - anos, à vezes décadas. ${ }^{21}$

Ele mesmo apresenta uma solução ao caso concreto:

Se a finalidade é harmonizar a jurisprudência e eliminar a sobrecarga de processos, o caminho seria outro. Deveríamos investir mais em soluções consensuais e extrajudiciais (acordos ou transações homologadas por órgãos públicos); criar procedimentos verdadeiramente mais célere (soluções liminares obrigatórias nos processos); instituir responsabilidades civis e penais extremamente sérias e efetivas para quem calasse ou negasse a verdade nos processos judiciais; impor sanções efetivas aos recursos improvidos, de forma que as partes pensassem duas vezes antes de recorrer, quando quisessem apenas procrastinar a solução do processo. ${ }^{22}$

Já Ricardo Castilho dispõe que:

Não é difícil perceber, nos organismos sociais diversos, que a educação constitui ponto central na afirmação dos direitos e deveres de Justiça. Já na obra de Sócrates, posteriormente, na de Aristóteles, fica evidente a necessidade de se proceder a uma boa educação básica. Para os filósofos helênicos, esta tarefa deveria ser bem desenvolvida para que os indivíduos pudessem entender e obedecer aos ditames do Bem Comum, identificados como as condutas virtuosas prescritas em lei - esta, consagrada da supremacia do interesse social sobre o individual. $^{23}$

Tais apresentações não representam qualquer novidade ou modificação dos panoramas atuais. O texto constitucional, no seu artigo 205, é disposto que, a educação:

A educação, direito de todos e dever do Estado e da família, será promovida e incentivada com a colaboração da sociedade, visando ao pleno desenvolvimento da pessoa, seu preparo para o exercício da cidadania e sua qualificação para o trabalho. $^{24}$

Para José Afonso da Silva,

Um regime de justiça social será aquele em que cada um deve poder dispor dos meios materiais de viver confortavelmente segundo as exigências de sua natureza física, espiritual e política. Não aceita as profundas desigualdades, a

\footnotetext{
${ }^{21}$ MAZZILLI, Hugo Nigro. O acesso à justiça e o Ministério Público. 5 ed. rev. ampl. e atual. São Paulo: Saraiva, 2007, p. 60.

${ }_{22}$ MAZZILLI, Hugo Nigro. O acesso à justiça e o Ministério Público. 5 ed. rev. ampl. e atual. São Paulo: Saraiva, 2007, p. 62.

23 CASTILHO, Ricardo. Justiça social e distributiva: desafios para concretizar direitos sociais. São Paulo: Saraiva, 2009, p. 118.

24 BRASIL. Constituição (1988). Constituição Federal da República Federativa do Brasil. Brasília: Senado, 1988.
} 
pobreza absoluta e a miséria. O reconhecimento dos direitos sociais, como instrumentos de tutela dos menos favorecidos, não teve até aqui a eficácia necessária para equilibrar a posição de inferioridade que os impede o efetivo exercício das liberdades garantidas. ${ }^{25}$

Diante disso, a necessidade de uma atuação mais condizente, não só dos órgãos públicos, como também dos privados, se mostra essencial para materializar as necessidades e anseios da coletividade. Como exemplo desta efetivação da justiça social tem-se a assistência jurídica gratuita, possibilitando o acesso a uma ordem jurídica justa, ao menos minimizando as diferenças sociais, por meio de uma inserção cidadã, na qual o Estado, por exemplo, por meio da Defensoria Pública, dispõe da prestação jurisdicional necessária, possibilitando assim a erradicação da hipossuficiência cívica, no ponto de vista social e financeiro. ${ }^{26}$

Segundo Luís Roberto Barroso, “[...] o intérprete constitucional deve ter compromisso com a efetividade da Constituição" 27 , possibilitando assim uma materialização dos dispositivos então existentes.

André Ramos Tavares assim se manifestou: “[...] a linguagem deve ser-lhe próxima, vale dizer, há de se privilegiar o emprego da linguagem comum". ${ }^{28}$ Diante disso, fundamental a aproximação do teórico com o prático, possibilitando assim uma melhor adequação dos dispositivos, materializando assim os preceitos ali dispostos. A linguagem, veículo de comunicação das informações é outro ponto fundamental de se analisar, vez que a sua apresentação se mostra essencial já que a sua facilitação promove, ainda que primariamente, um contato mais fácil por parte da população.

Diante de tudo que foi apresentado na presente abordagem, se mostra extramente relevante informar a população de seus direitos, por meio de atuações efetivas e capazes de conscientizarem as pessoas dos deveres e garantias que possuem, evitando a concentração deste conhecimento nas mãos de poucas pessoas.

O Estado teria um grupo de pessoas mais críticas e mais conscientes de tudo, capazes de promoverem uma melhoria vertiginosa na nação. A educação, apresentada no texto constitucional $^{29}$ por diversas vezes, inclusive com um capítulo específico, o terceiro, deve traduzir tal disposição como uma dimensão global e indicar uma formação dos indivíduos, com o

25 DA SILVA, José Afonso. Curso de direito constitucional positivo. 36 ed. São Paulo: Saraiva, 2013, p. 661.

${ }^{26}$ ALVAREZ, Anselmo Pietro. O estado social democrático de direito no Brasil e a assistência jurídica integral gratuita. In: Revista dos Tribunais, ano 95, junho de 2006, v. 848, São Paulo: Revista dos Tribunais, p. 39.

${ }_{27}$ BARROSO, Luís Roberto. Interpretação e aplicação da Constituição: fundamentos de uma dogmática constitucional transformadora. 7 ed. rev. São Paulo: Saraiva, 2009, p. 375.

${ }_{28}$ TAVARES, André Ramos. Curso de direito constitucional. 9. ed. rev. e atual. São Paulo: Saraiva, 2001, p. 106

29 BRASIL. Constituição Federal da República Federativa do Brasil. Brasília: Senado, 1988.

"Art. $6^{\circ}$ São direitos sociais a educação, a saúde, a alimentação, o trabalho, a moradia, o lazer, a segurança, a previdência social, a proteção à maternidade e à infância, a assistência aos desamparados, na forma desta Constituição."

"Art. 150. Sem prejuízo de outras garantias asseguradas ao contribuinte, é vedado à União, aos Estados, ao Distrito Federal e aos Municípios: [...] VI - instituir impostos sobre: [...] c) patrimônio, renda ou serviços dos partidos políticos, inclusive suas fundações, das entidades sindicais dos trabalhadores, das instituições de educação e de assistência social, sem fins lucrativos, atendidos os requisitos da lei;"

"Art. 205. A educação, direito de todos e dever do Estado e da família, será promovida e incentivada com a colaboração da sociedade, visando ao pleno desenvolvimento da pessoa, seu preparo para o exercício da cidadania e sua qualificação para o trabalho." 
papel de homem no momento histórico na qual pertence a sua própria existência. ${ }^{30}$ Ocorre que o interesse de um grupo, que comanda o país, parece que não esta interessada nesta modificação, buscando manter a situação como esta hoje.

A simples mudança legislativa não se mostra capaz de alterar e realmente e a lentidão dos processos. Mostra-se essencial uma modificação na própria concepção social, cultura e psicológica da própria sociedade. ${ }^{31}$ Indispensável pensar nas demandas apresentadas não somente em face dos problemas já dispostos, mas também nos acontecimentos prévios, na própria cultura e na própria apresentação dos problemas, por exemplo, por meio da utilização de procedimentos alternativos, como por exemplo, a mediação e a conciliação.

O próprio descaso da população em face do Poder Judiciário é consequência direta e imediata pela própria ineficiência deste, provocando a não concretização de suas garantias, mesmo quando se mostra evidenciado o abuso dos direitos. Somado a isso, os instrumentos de efetivação dos direitos e deveres inerentes a todos se mostram limitados a um pequeno grupo de pessoas, especialmente face a concentração do conhecimento técnico e das barreiras econômicas, culturais e sociais dispostas.

A absorção dos direitos só se mostrará capaz de suprir as necessidades atuais, quando todos os poderes do Estado conseguirem realmente suprirem o anseios de uma sociedade que a cada dia se modifica e se altera, aliada a criação de mecanismos acessíveis a todos, de modo indeterminado e realmente eficazes.

A simples divulgação de noções básicas do direito, por meio do rádio, da televisão e da internet se mostram um embrião interessante e importante, ao aproximar as pessoas do conhecimento ali disposto. O que tem causado certo receio é a apresentação sem critério destas informações, o que dificulta não só o acesso a uma informação confiável, como especialmente acaba por apresentar ainda maiores dificuldades às pessoas, que ao invés de serem informadas, acabam por receber algo incorreto, causando ainda mais indignação.

Outro fator que muitas vezes é deixado de lado, especialmente pela questão do hábito forense, são os obstáculos psicológicos. A arquitetura imponente dos fóruns; a vestimenta típica dos membros do Poder Judiciário e dos advogados ${ }^{32}$; a linguagem complexa e até mesmo prolixa são apenas alguns apontamentos feitos para demostrar o quão massificador é esta apresentação para as pessoas que estão alheias a ele. A apresentação mais simples e menos rígida se mostra uma via muito prudente para modificação deste cenário.

Relevante realizar uma releitura dos dispositivos existentes, por meio de uma nova sistemática, voltada para a efetivação dos valores consagrados constitucionalmente, possibilitando assim a pacificação social ${ }^{33}$ se mostra necessário e até mesmo em caráter urgente.

\section{CONCLUSÃO}

Portanto, resta mais do que evidenciada a necessidade de modificações no método de transmissão do conhecimento jurídico, face aos anseios sociais, especialmente com relação aos mais necessitados, que estão à margem da sociedade muitas vezes. A apresentação de métodos diferenciados e ao mesmo tempo relevantes para esta modificação de pensamento se mostra essencial para que exista uma aproximação entre a sociedade e o próprio Estado. Que as pessoas

3o ROESLER, Heloísa Maria Kiehl Noronha. Estudo analítico da qualidade do serviço educacional na região sul da cidadã de São Paulo. (Tese de Doutorado em Administração: Universidade Presbiteriana Mackenzie), São Paulo, 1998, p. 30.

${ }^{31}$ MORALLES, Luciana Camponez Pereira. Acesso à justiça e princípio da igualdade. Porto Alegre: Sergio Antonio Fabris, 2006, p. 65.

$3^{2}$ MORALLES, Luciana Camponez Pereira. Acesso à justiça e princípio da igualdade. Porto Alegre: Sergio Antonio Fabris, 2006, p. 79.

33 MARINONI, Luiz Guilherme. Novas linhas do processo civil. 4. Ed. São Paulo: Malheiros, 2000, p. 103. Revista de Direito Brasileira | São Paulo, SP | v. 14 | n. 6 | p. 128- 138 | maio/ago. 2016 
conheçam de seus direitos e obrigações de forma irrestrita, e não somente em situações pontuais, quando realmente sofrem uma violação, e mesmo assim isso é feito de forma segmentada.

Diante de tudo que foi apresentado na presente abordagem, resta claro a necessidade de se repensar o atual cenário brasileiro, especialmente no que tange à educação. A disseminação do conhecimento, para todos os interessados, indistintamente é uma saída extremamente útil, ao aproximar, por exemplo, o direito do quotidiano das pessoas, de forma efetiva. Fazendo com que compreendam seus direitos e suas obrigações quotidianas, de modo a não sofrerem abusos e prejuízos, devido à ignorância que muitos possuem.

Portanto, não basta assegurar os direitos, de maneira formal apenas, mas de tutelar para que eles sejam materializados. Exemplo disso é a educação. Insuficiente o Estado garantir apenas o acesso às crianças e adolescentes o contato com a escola, sem que essa realmente ofereça uma infraestrutura e material apto para promover o desenvolvimento destes seres humanos em crescimento.

\section{REFERÊNCIAS BIBLIOGRÁFICAS}

ABDO, Helena. Mídia e processo. São Paulo: Saraiva, 2011.

ALVAREZ, Anselmo Pietro. O estado social democrático de direito no Brasil e a assistência jurídica integral gratuita. In: Revista dos Tribunais, ano 95, junho de 2006, v. 848, São Paulo: Revista dos Tribunais.

BARROSO, Luis Roberto. Começo da história. A nova interpretação constitucional e o papel dos princípios no direito brasileiro. In SILVA, Virgílio Afonso da (org.). Interpretação Constitucional. São Paulo: Malheiros, 2005.

- Interpretação e aplicação da Constituição: fundamentos de uma dogmática constitucional transformadora. 7 ed. rev. São Paulo: Saraiva, 2009.

BECKER, Alfredro Augusto. Teoria geral do direito tributário. São Paulo: Saraiva, 1963.

BONAVIDES, Paulo. Curso de Direito Constitucional. 7. ed. São Paulo: Malheiros, 1997.

BRASIL. Constituição (1988). Constituição Federal da República Federativa do Brasil. Brasília: Senado, 1988.

Brasília: Senado, 2013.

CANOTILHO, José Joaquim Gomes. Direito constitucional. Coimbra: Almedina, 1989.

CAPPELLETTI, Mauro; GARTH, Bryant. Acesso à justiça. Trad. Ellen Gracie Northfleet. 1. ed. Porto Alegre: Sergio Antonio Fabris Editor, 1988.

CASTILHO, Ricardo. Justiça social e distributiva: desafios para concretizar direitos sociais. São Paulo: Saraiva, 2009.

DA SILVA, José Afonso. Curso de direito constitucional positivo. 36 ed. São Paulo: Saraiva, 2013. 
DE CARVALHO, Luiz Gustavo Grandinetti Castanho. Liberdade de informação e o direito difuso à informação verdadeira. 2. ed. Rio de Janeiro: Renovar, 2003.

DE MORAES, Bernardo Ribeiro. A imunidade tributária e seus novos aspectos. In MACHADO, Hugo de Brito (coord.). Imunidades tributárias. São Paulo: CEU/Revista dos Tribunais, 1998.

DE MORAES, Humbero Peña; DA SILVA, José Fontenelle Teixeira. Assistência judiciária: sua gênese, sua história e a função protetiva do Estado. 2. ed. Rio de Janeiro: Liber Juris, 1994.

FARIAS, Edilson. Liberdade de expressão e comunicação: teoria e proteção constitucional. São Paulo: Revista dos Tribunais, 2004.

FRANCO, Afonso Arinos de Melo. Direito constitucional, teoria constitucional, as constituições do Brasil. Rio de Janeiro: Revista Forense, 1976.

HABERMAS, Junger. Historia y crítica de la opinión pública: la transformación estructural de la vida pública. 4. ed. Barcelona: Gustavo Gilo Eds., 2005.

HESSE, Konrad. Escritos de Derecho Consticional. Trad. Pedro Cruz Villalon, Madrid: Centro de Estudios Constitucionales, 1992.

MARINONI, Luiz Guilherme. Novas linhas do processo civil. 4. Ed. São Paulo: Malheiros, 2000.

MAZZILLI, Hugo Nigro. O acesso à justiça e o Ministério Público. 5 ed. rev. ampl. e atual. São Paulo: Saraiva, 2007.

MORALLES, Luciana Camponez Pereira. Acesso à justiça e princípio da igualdade. Porto Alegre: Sergio Antonio Fabris, 2006.

ROESLER, Heloísa Maria Kiehl Noronha. Estudo analítico da qualidade do serviço educacional na região sul da cidadã de São Paulo. (Tese de Doutorado em Administração: Universidade Presbiteriana Mackenzie), São Paulo, 1998.

TAVARES, André Ramos. Curso de direito constitucional. 9. ed. rev. e atual. São Paulo: Saraiva, 2001.

WATANABE, Kazuo. Acesso à justiça e sociedade moderna. In: Participação e Processo. 1 ed. São Paulo: Revista dos Tribunais, 1988. 